\title{
The Effect of Ascorbic Acid over the Etoposide- and Temozolomide-Mediated Cytotoxicity in Glioblastoma Cell Culture: A Molecular Study
}

\author{
Dilek GOKTURK¹, Hasim KELEBEK², Seda CEYLAN¹, Dervis Mansuri YILMAZ³ \\ ${ }^{1}$ Adana Science and Technology University, Faculty of Engineering and Natural Sciences, Department of Bioengineering, Adana, Turkey \\ ${ }^{2}$ Adana Science and Technology University, Faculty of Engineering and Natural Sciences, Department of Food Engineering, Adana, Turkey \\ ${ }^{3}$ Cukurova University, Faculty of Medicine, Department of Neurosurgery, Adana, Turkey
}

\section{ABSTRACT}

AIM: Glioblastoma (GBM) is one of the lethal central nervous system tumors. One of the widely used chemical agents for the treatment of glioblastoma is temozolomide. It is an orally administered, deoxyribonucleic acid (DNA) alkylating agent. DNA alkylation triggers the death of tumor cells. However, some tumor cells are able to repair this type of DNA damage and thus lower the therapeutic effect of temozolomide. Laboratory and clinical studies indicate that temozolomide's anticancer effects might be strengthened when combined with other chemotherapeutic agents like etoposide or antioxidant agents like ascorbic acid. In this study, we aimed to evaluate the cytotoxic and oxidative stress effects of ascorbic acid (1000 $\mu \mathrm{M})$, temozolomide (100 $\mu \mathrm{M})$ and etoposide $(25 \mu \mathrm{M})$ agents alone and in dual and triple combinations in a glioblastoma U87 MG cell culture.

MATERIAL and METHODS: The cytotoxic and oxidative stress effects were investigated by the 3-(4,5-dimethylthiazol-2-yl)-2,5diphenyltetrazolium bromide (MTT) and liquid chromatography tandem-mass spectrometry (LC-MS/MS) analysis methods.

RESULTS: Cytotoxicity tests showed that etoposide, temozolomide, "etoposide+ascorbic acid", "temozolomide+ascorbic acid", "temozolomide+etoposide" and "temozolomide+etoposide+ascorbic acid" combinations have anti-proliferative effects. The maximum anti-proliferation response was observed in the "temozolomide+etoposide+ascorbic acid"-added group. Similarly LCMS/MS analyses showed that minimum oxidative DNA damage occurred in the "temozolomide+etoposide+ascorbic acid"-added group.

CONCLUSION: Ascorbic acid decreases the cytotoxic and genotoxic effect of etoposide and etoposide-temozolomide combination but it has no meaningful effect on temozolomide's toxicity.

KEYWORDS: Glioblastoma, Ascorbic acid, Cytotoxicity, Etoposide, Temozolomide

\section{INTRODUCTION}

A ny tumor that arises from the glial or supportive tissue of the brain or the spinal cord is called "glioma". One of the types of glioma is astrocytoma. Astrocytomas arise from astrocytes, the star-shaped cells, and are graded to describe their degree of abnormality. The most common grading system uses a scale of I to IV $(15,16,18)$.
Glioblastoma (GBM, WHO grade IV) accounts for $50 \%$ of all the intracranial tumors and $70 \%$ of the primary malignant brain tumors. Although GBM often occurs in late adulthood $(70 \%$ at a mean age of 53 years), up to $8.8 \%$ occur during childhood. Absence of specific symptoms is the predominant reason for which tumors are often detected at advanced stages, leading to poor prognosis with a mean survival of 1 year for GBM (18). 
Ascorbic acid is a water-soluble antioxidant with the potential to protect biochemical molecules from oxidative damage. More recently, in vitro studies on animal models found intravenous ascorbic acid at high doses to be promising in the treatment of cancers. More than three decades ago, benefits of megadose ascorbic acid treatment for patients with advanced cancer were claimed. Nonetheless, its effects have not been confirmed by an adequate number of studies (2).

For decades, the basic malignant glioma treatment was radiotherapy followed by chemotherapy with the use of alkylating agents such as nitrosoureas, procarbazine and more recently temozolomide (24). Temozolomide is an orally bioavailable, methylating agent that can pass through the blood-brain barrier and trigger the death of tumor cells. However, some tumor cells can repair this type of deoxyribonucleic acid (DNA) damage, and therefore diminish the efficiency of the therapy. Laboratory and clinical studies indicate that temozolomide's anti-cancer effects might be strengthened when combined with other chemotherapeutic agents like etoposide $(5,12)$.

Etoposide (VP-16,4' - dimethylepipodophylloxin-9-(4,6-O-ethylidene - beta - D glucopyranoside)) is an anti-cancer agent, which is successfully and extensively used in treatments of various types of cancers in children and adults. It forms a ternary complex with the DNA and the topoisomerase II enzyme and so causes DNA strands to break $(6,12)$.

In laboratory studies, the effects of chemotherapeutics can be tested by cytotoxicity and genotoxicity assays in the cell cultures. Cytotoxicity refers to the ability of chemicals to destroy living cells while genotoxicity refers to the ability of chemicals to damage the genomic DNA. Cytotoxicity assays measure cell viability; genotoxicity assays measure the DNA lesions that are the product of the DNA damage.

For cytotoxicity assays, the 3-(4,5-dimethylthiazol-2-yl)-2,5diphenyltetrazolium bromide (MTT) tetrazolium reduction assay is generally used. Viable cells with active metabolism convert the MTT into a purple-colored formazan product with an absorbance near $570 \mathrm{~nm}$. When cells die, they do not have the ability to convert the MTT into formazan. This color formation serves as a useful marker of the living cells (17).

For genotoxicity assays, 8-oxo-7,8-dihydroguanine (8-OH$\mathrm{dG}$, which is an oxidative DNA damage product, can be measured by liquid chromatography tandem-mass spectrometry (LC-MS/MS). Reactive oxygen species (ROS) are generated during the normal cellular metabolism and normally detoxified by anti-oxidant enzymes. Oxidative stress occurs when the endogenous ROS detoxification pathways are inadequate because of some situations, e.g. viral and bacterial infections, inflammation, metabolism of drugs such as etoposide, exposure to some chemicals, or smoking. During oxidative stress, ROS can damage cellular DNA. These endogenous DNA lesions are genotoxic and can induce mutations. The most extensively studied lesion is the formation of $8-\mathrm{OH}-\mathrm{dG}$. As the lesion is relatively easily formed, mutagenic and therefore a potential biomarker of oxidative DNA damages, 8-OH-dG, can be measured by LC-MS/MS to evaluate the oxidative DNA damage effects, in other words the genotoxic effects of chemicals $(14,20-22)$.
ROS are generated during normal cellular metabolism and normally detoxified by anti-oxidant enzymes. Oxidative stress occurs when the endogenous ROS detoxification pathways are inadequate because of some situations, e.g. viral and bacterial infections, inflammation, metabolism of drugs such as etoposide, exposure to some chemicals, or smoking. During oxidative stress, ROS can damage cellular DNA $(18,19,21,22)$.

In this study, we aimed to analyze the cytotoxic and genotoxic effects of ascorbic acid over etoposide and temozolomide in a glioblastoma cell culture. For cytotoxicity and genotoxicity analysis, MTT and LC-MS/MS experiments were performed.

\section{MATERIAL and METHODS}

\section{Cell Culture}

Studies were carried out in the human glioblastoma cell line U87MG (HTB-14). They were cultured in Dulbecco's Modified Eagle Medium (DMEM) with stable L-glutamine and sodium pyruvate (Life Technologies, Cat No:22320-030) supplemented with 10\% fetal bovine serum (Life Technologies, Cat No:10082147) without antibiotics in a humidified incubator at $37^{\circ} \mathrm{C}$ and $5 \% \mathrm{CO}_{2}$ atmosphere. Confluent cells were detached with trypsin-ethylenediaminetetraacetic acid (EDTA) solution (Life Technologies, Cat No:R-001-100) in calcium-free phosphate buffered saline (PBS) and counted in a Neubauer chamber.

\section{Cytotoxicity Assay}

The effects of ascorbic acid $(1000 \mu \mathrm{M})$, temozolomide (100 $\mu \mathrm{M})$ and etoposide $(25 \mu \mathrm{M})$ agents alone, in dual and triple combinations on the viability of glioblastoma cell line (U87MG) were studied after 48, 96 and 144 hours of treatment in triplicate. Cells were seeded into 24 -well plates in a volume of $500 \mu \mathrm{l}$ per well at a density of 100,000 cells/well and grown at $37^{\circ} \mathrm{C}$ in a humidified $5 \% \mathrm{CO}_{2}$ incubator. Cell proliferation was measured by a quantitative colorimetric assay using MTT (3). The data was expressed as a percentage of control.

MTT (Sigma Cat No:M5655) powder was dissolved in PBS at the concentration of $1 \mathrm{mg} / \mathrm{ml}$. Single agent and dual and triple combinations of ascorbic acid $(1000 \mu \mathrm{M})$, temozolomide $(100 \mu \mathrm{M})$ and etoposide $(25 \mu \mathrm{M})$-added cells were incubated for 48,96 and 144 hours at $37^{\circ} \mathrm{C}$ in a humidified $5 \% \mathrm{CO}_{2}$ incubator. After the incubation period, growth medium was removed and $400 \mu \mathrm{L} \mathrm{MTT} \mathrm{solution}(1 \mathrm{mg} / \mathrm{ml})$ was added to each well. They were incubated for nearly 1 hour until purple precipitates became visible. After the development of visible purple precipitates, each well was filled with $1000 \mu \mathrm{L}$ dimethyl sulfoxide (DMSO) and isopropanol (1:5) mixture. Plates were incubated for nearly 1 hour until the purple precipitate completely dissolved. Dissolved formazan crystals of each well were measured at $570 \mathrm{~nm}$ in the spectrophotometer (Shimadzu UV-VIS, UVmini-1240).

\section{Oxidative DNA Damage Analysis}

In this study, the DNA damage product $8-\mathrm{OH}-\mathrm{dG}$ was measured by LC-MS/MS to evaluate the oxidative DNA damage effects of chemicals. Firstly, DNA isolations were performed. After that, DNA samples were enzymatically hydrolyzed and analyzed by LC-MS/MS. 


\section{DNA isolation}

DNA samples from cell cultures were extracted according to the instruction manual of the extraction kit (Zymo Research, Cat No:D3025). Concentrations of the DNA samples were measured by Qubit 2.0 fluorometer (Invitrogen, Cat No:Q32866).

\section{Enzymatic hydrolysis of the DNA}

DNA hydrolysis was performed by adding a mixture of DNase I (1U/50 $\mu \mathrm{l})$ to equal DNA sample solutions, followed by incubation for $8-10$ hours at $37^{\circ} \mathrm{C}$ according to enzyme's instruction manual (MN, Cat No:740963).

\section{Mass Spectrometry}

Samples were filtered through a $0.45-\mu$ m pore sized membrane before injection. The Agilent 1100 high performance liquid chromatography (HPLC) system (Agilent Technologies, Palo Alto CA, USA) operated by Windows NT based ChemStation software was used. The system consisted of a binary pump, degasser and auto sampler. The column used was a Phenomenex Luna reversed-phase $\mathrm{C}-18$ column (4.6 mm $\times 250$ $\mathrm{mm}, 5 \mu \mathrm{m})$ (Torrance, CA, USA). The mobile phase consisted of two solvents: Solvent A, water/formic acid (99:1; v/v) and Solvent B, acetonitrile/solvent A (60:40; v/v). Compounds were eluted in the following environment: $0.5 \mathrm{~mL} / \mathrm{min}$ flow rate and the temperature was set at $25^{\circ} \mathrm{C}$, isocratic conditions from 0 to 10 minutes with $0 \% \mathrm{~B}$, gradient conditions from $0 \%$ to $5 \%$ $B$ in 30 minutes, from $5 \%$ to $15 \%$ B in 18 minutes, from $15 \%$ to $25 \%$ B in 14 minutes, from $25 \%$ to $50 \%$ B in 31 minutes, from $50 \%$ to $100 \%$ B in 3 minutes, followed by washing and reconditioning the column. Triplicate analyses were performed for each sample. The identification and assignation of each compound was confirmed by LC-MS/MS analysis. Agilent 6430 LC-MS/MS spectrometer equipped with an electrospray ionization source was used. The electrospray ionization mass spectrometry detection was performed with the following optimized parameters: capillary temperature $400^{\circ} \mathrm{C}$; drying gas $\mathrm{N}_{2} 12 \mathrm{~L} / \mathrm{min}$; nebulizer pressure, $45 \mathrm{psi}$ (10). Data collection was performed with the use of multiple reactions monitoring (MRM) method that monitors specific mass transitions only during the preset retention times. Dynamic MRM also has the ability to simultaneously perform electrospray injection (ESI) in both the positive and the negative mode, allowing for the analysis of different phenolic classes within a single chromatographic run. Transition of m/z $284-\mathrm{m} / \mathrm{z} 168$ (for 8-oxo-dGuo) was monitored.

\section{RESULTS}

Cytotoxicity was determined by the MTT assay. MTT assay data (Figure 1) revealed that ascorbic acid decreased the number of cells within 48 hours. Within 96 and 144 hours, however, it was observed that the ascorbic acid had no cytotoxic effect. In addition, the cell numbers were increased. Temozolomide and etoposide decreased the cell numbers within 48, 96 and 144 hours alone and in dual combinations. It is assumed that the ascorbic acid had an inhibitory impact over temozolomide and etoposide's cytotoxic effects. Interestingly, the best cytotoxic effect was achieved when the ascorbic acid, temozolomide and etoposide triple combination was applied. The results indicate that the utilization of ascorbic acid increases cell proliferations in the temozolomide and etoposide-added cell

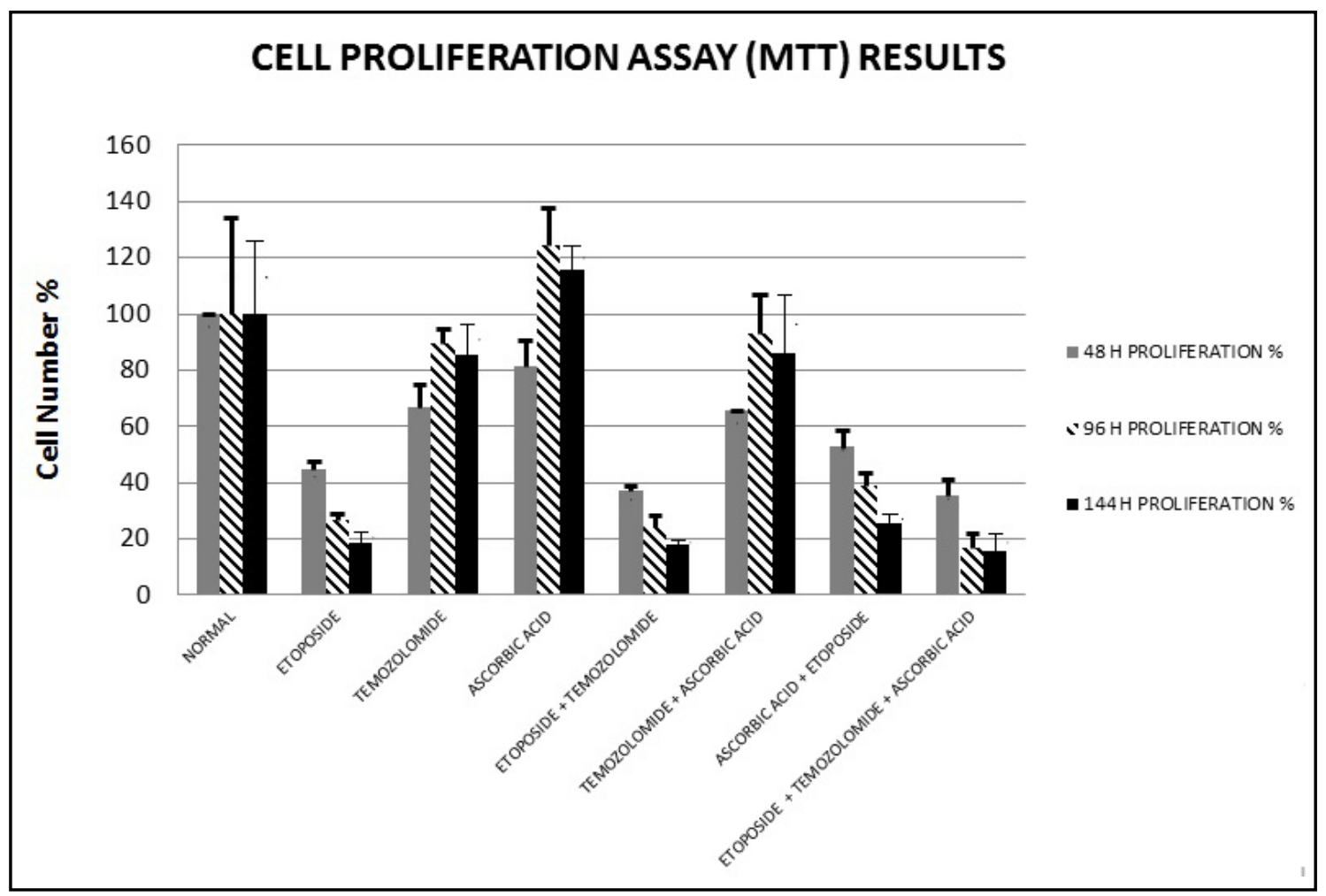

Figure 1: Cell proliferation graphics determined by MTT assay after 48 , 96 and 144 hours incubation with Ascorbic acid (1000 $\mu \mathrm{m})$, Temozolomide $(100 \mu \mathrm{m})$ and Etoposide $(25 \mu \mathrm{m})$. 
cultures separately. Furthermore, ascorbic acid exhibited cell proliferation inhibitory effect in the etoposide, temozolomide and ascorbic acid-added group and the most cytotoxic effect was noted in the group applied that triple chemotherapeutic combination.

A sensitive method for the detection of 8-oxo-dG in DNA samples has been optimized. It utilizes immunoaffinity column purification of 8-oxo-dG followed by LC-MS/MS MRM mode analysis. The 8 -oxo-dGuo base product (an oxidative
DNA damage product) ion at $\mathrm{m} / \mathrm{z} 168$ was monitored following cleavage of the glycosidic bond of the 8-oxo-dG $(\mathrm{M}+\mathrm{H})+$ ion at $\mathrm{m} / \mathrm{z} 284$. DNA damage analysis data that was obtained from LC-MS/MS experiments (Figure 2A, B) showed that ascorbic acid had an impact that increased the 8-oxo-dGuo concentration. It increased genotoxicity when used by itself but it decreased 8-oxo-dGuo concentrations. Therefore, it increased genotoxicity in the etoposide and etoposide-temozolomide combination-added groups. It was also observed that temozolomide had decreasing effect on 8-oxo-dGuo concentration

(A)

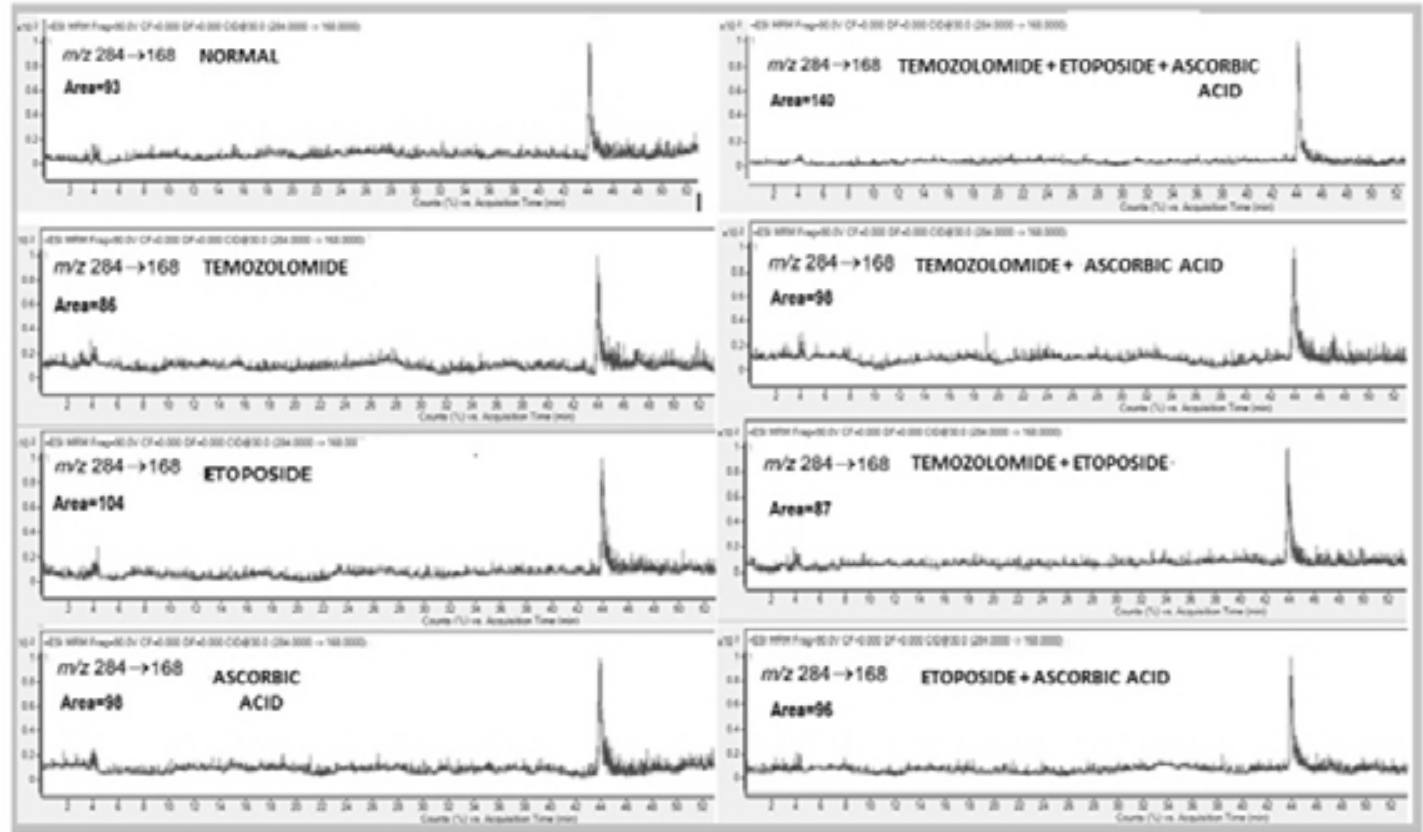

(B)

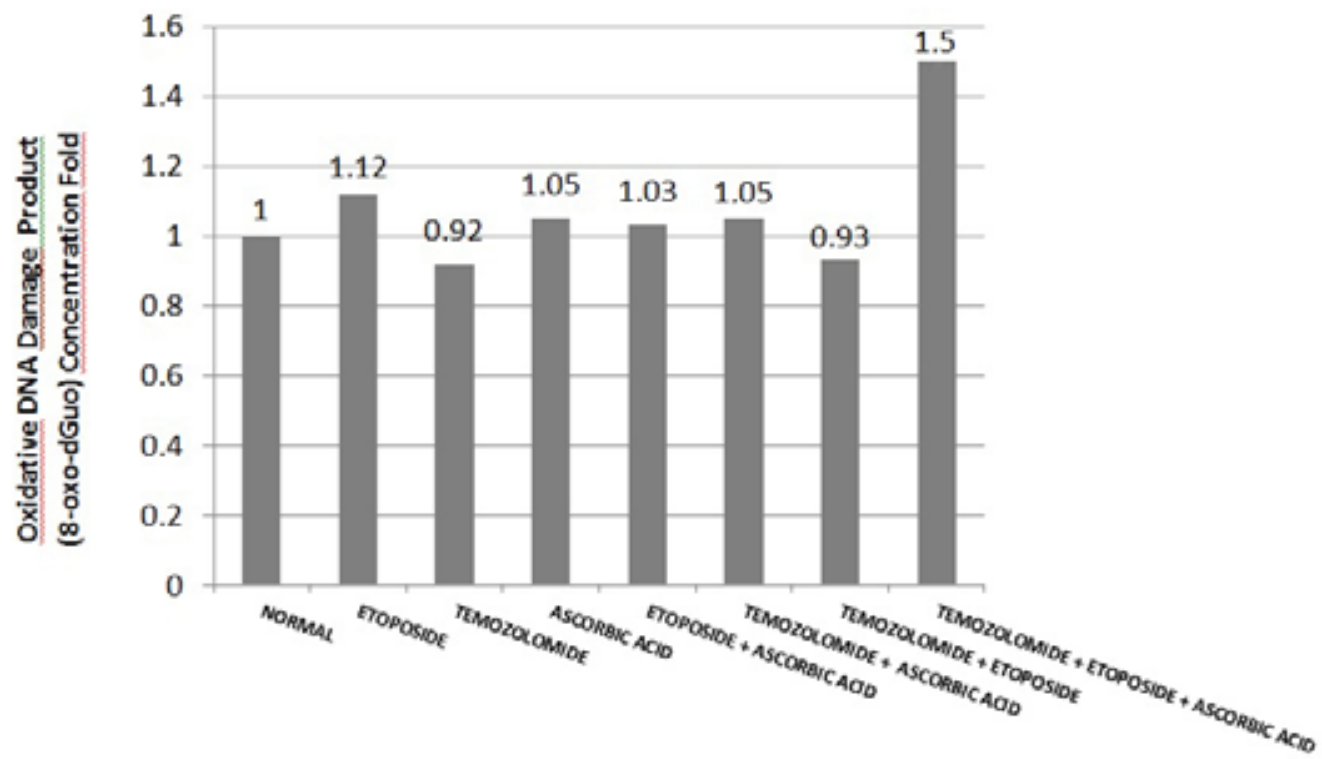

Figure 2: A) Oxidative DNA Damage Product (8-oxo-dGuo) analysis LC-MS/MS Chromotogram after 96 hours incubation with Ascorbic acid $(1000 \mu \mathrm{m})$, Temozolomide $(100 \mu \mathrm{m})$ and Etoposide $(25 \mu \mathrm{m})$. B) DNA damage product (8-oxo-dGuo) concentration fold graphics determined by LC/MS analysis after 96 hours incubation with Ascorbic acid (1000 $\mu \mathrm{m})$, Temozolomide (100 $\mu \mathrm{m})$ and Etoposide $(25 \mu \mathrm{m})$. 
and no influence was observed on genotoxicity in the ascorbic acid-added group.

\section{DISCUSSION}

Although there have been many reports of ascorbic acid, etoposide and temozolomide's single and dual effects on many cancers, including GBM $(4,5,7,23)$, no studies have reflected the use of triple combinations in malignant glioblastoma cell lines. In this study, the effect of ascorbic acid, etoposide and temozolomide on glioblastoma cell proliferation was examined by exposing U87 MG cells to ascorbic acid (1000 $\mu \mathrm{M})$, temozolomide $(100 \mu \mathrm{M})$ and etoposide $(25 \mu \mathrm{M})$ for 48 , 96 , and 144 hours in DMEM medium containing 10\% serum.

Genotoxicity data obtained from LC-MS/MS experiments (Figure 2A, B) have shown that ascorbic acid alone has an impact that increases oxidative DNA damage. The findings were confirmed in a number of studies performed on different cell cultures in the literature. For instance, it was reported that incubation of human lymphocytes, neonatal fibroblasts, and leukemia cell line with ascorbic acid for 1 hour resulted in DNA single-strand breaks (20).

Consistent with the cytotoxicity data, genotoxicity was decreased in the etoposide and etoposide-temozolomide combination-added groups. The strongest genotoxic effect was observed when the combination of ascorbic acid, etoposide and temozolomide was applied to the cells. It can be said that cytotoxic and genotoxic effects of temozolomide and etoposide were decreased by ascorbic acid, but the highest cytotoxicity with the slightest genotoxicity was achieved with use of the triple combination. The reason might be that, in the increased genotoxic circumstances, ascorbic acid makes cells stop the cell cycle and go into senescence. However, when relatively less genotoxicity occurs, ascorbic acid can protect cells from DNA damage and cytotoxic effects.

While ascorbic acid can protect DNA against the damage induced by various chemicals $(1,8)$, some reports indicated that it can be genotoxic $(9,20)$. Similar results were obtained from our experiments that aimed to test the effect of ascorbic acid over the chemotherapeutic drugs etoposide and temozolamide in a glioblastoma cell line U87 MG. It was noted that ascorbic acid had a genotoxic potential when used by itself.

In addition, it was observed that temozolomide had a decreasing effect on 8-oxo-dGuo concentration and had no influence over the genotoxic effect in the ascorbic acid-added group. The above may be explained as follows. The therapeutic benefit of temozolomide depends on its ability to alkylate/ methylate DNA, which most often occurs at the $\mathrm{N}$ (nitrogen) 7 and $O$ (oxygen) 6 positions of guanine residues, causing a base pair mismatch. This methylation damages the DNA, and when mismatch repair (MMR) enzymes attempt to remove the 8-oxo-dGuo adduct, they produce single and double-strand breaks in the DNA and trigger cell death $(11,13)$. Removing the methyl guanine adducts causes a decrease in the guanine residue concentrations. As such, the production of 8-oxodGuo adducts diminishes.

\section{CONCLUSION}

Ascorbic acid decreases the cytotoxic and genotoxic effect of the etoposide and etoposide-temozolomide combination, but it has no meaningful effect on temozolomide's toxicity. To disclose the effects of ascorbic acid on the DNA damages and cytotoxicity, further studies with different chemotherapeutic drugs and cancer cell lines are needed. Cell cycle experiments are also required to clarify the effects of using ascorbic acid alone and in combinations with chemotherapeutic drugs on cell proliferation.

\section{ACKNOWLEDGEMENT}

This work was supported by Scientific Research Projects Fund of Adana Science and Technology University (Project no: MÜHDBF.BiYO.2014-5). The authors thank Assist. Prof. Tuğba Bağcı Önder from Koç University, Faculty of Medicine, Molecular Biology Department for kindly donating the $U 87$ MG Glioblastoma cell line.

\section{- REFERENCES}

1. Blasiak J, Kowalik J: Protective action of Vitamin $\mathrm{C}$ against DNA damage induced by selenium-cisplatin conjugate. Acta Biochim Pol 48: 233-240, 2001

2. Cameron E, Pauling L: Supplemental ascorbate in the supportive treatment of cancer: Prolongation of survival times in terminal human cancer. Proc Natl Acad Sci USA 73:36853689, 1976

3. Carmichael J, DeGraff WG, Gazdar AF, Minna JD, Mitchell JB: Evaluation of a tetrazolium-based semi-automated colorimetric assay: Assessment of chemosensitivity testing. Cancer Res 47:936-942, 1987

4. Chen Q, Espey MG, Sun AY, Pooput C, Kirk KL, Krishna MC, Khosh DB, Drisko J, Levine M: Pharmacologic doses of ascorbate act as a prooxidant and decrease growth of aggressive tumor xenografts in mice. Proc Natl Acad Sci USA 105:11105-11109, 2008

5. Ebert BL, Niemerko E, Shaffer K, Salgia R: Use of Temozolomide with other cytotoxic chemotherapy in the treatment of patients with recurrent brain metastases from lung cancer. Oncologist 8:69-75, 2003

6. Ezoe S: Secondary leukemia associated with the anti-cancer agent, etoposide, a topoisomerase II inhibitor. Int J Environ Res Public Health 9: 2444-2453, 2012

7. Gokhalé P, Patel T, Morrison MJ, Vissers MC: The effect of intracellular ascorbate on the susceptibility of HL60 and Jurkat cells to chemotherapy agents. Apoptosis 11:1737-1746, 2006

8. Heaney ML, Gardner JR, Karasavvas N, Golde DW, Scheinberg DA, Smith EA, O'Connor OA: Vitamin C antagonizes the cytotoxic effects of antineoplastic drugs. Cancer Res 68:8031-8038, 2008

9. Herst PM, Broadley KWR, Harper JL, McConnell MJ: Pharmacological concentrations of ascorbate radiosensitize glioblastoma multiforme primary cells by increasing oxidative DNA damage and inhibiting G2/M arrest. Free Radic Biol Med 52:1486-1493, 2012 
10. Jiang $\mathrm{H}$, Zeng J, Titsch $\mathrm{C}$, Voronin $\mathrm{K}$, Akinsanya $\mathrm{B}$, Luo L, Shen H, Desai DD, Allentoff A, Aubry AF, Desilva BS, Arnold ME: Fully validated LC-MS/MS assay for the simultaneous quantitation of coadministered therapeutic antibodies in Cynomolgus Monkey serum. Anal Chem 85:9859-9867, 2013

11. Jiang G, Li LT, Xin Y, Zhang L, Liu YQ, Zheng JN: Strategies to improve the killing of tumors using temozolomide: Targeting the DNA repair protein MGMT. Curr Med Chem 19:3886-3892, 2012

12. Korones DN, Benita-Weiss M, Coyle TE, Mechtler L, Bushunow P, Evans B, Reardon DA, Quinn JA, Friedman H: Phase I study of temozolomide and escalating doses of oral etoposide for adults with recurrent malignant glioma. Cancer 97:1963-1968, 2003

13. Koumarianou A, Kaltsas G, Kulke MH, Oberg K, Strosberg JR, Spada F, Galdy S, Barberis M, Fumagalli C, Berruti A, Fazio $\mathrm{N}$ : Temozolomide in advanced neuroendocrine neoplasms: Pharmacological and clinical aspects. Neuroendocrinology 101:274-288, 2015

14. Mesaros C, Arora JS, Wholer A, Vachani A, Blair IA: 8-Oxo-2'Deoxyguanosine as a biomarker of tobacco smoking-induced oxidative stress. Free Radic Biol Med 53:610-617, 2012

15. Omuro A, De Angelis LM: Glioblastoma and other malignant gliomas: A clinical review. JAMA 310:1842-1850, 2013
16. Porter A: A dead end. A review of glioblastoma multiforme. Eukaryon 8: 64-68, 2012

17. Riss TL, Moravec RA, Niles AL, Duellman S, Benink HA, Worzella TJ, Minor L: Cell viability assays: Assay guidance manual. Eli Lilly \& Company and the National Center for Advancing Translational Sciences; 2013: 2-3

18. Shapiro WR, Shapiro JR: Biology and treatment of malignant glioma. Oncology (Williston Park) 12:233-246, 1998

19. Simon HU, Haj-Yehia A, Levi-Schaffer F: Role of reactive oxygen species (ROS) in apoptosis induction. Apoptosis 5:415-418, 2000

20. Singh NP: Sodium ascorbate induces DNA single-strand breaks in human cells in vitro. Mutat Res 375:195-203, 1997

21. Uttara B, Singh AV, Zamboni P, Mahajan RT: Oxidative stress and neurodegenerative diseases: A review of upstream and downstream antioxidant therapeutic options. Curr Neuropharmacol 7: 65-74, 2009

22. Valko M, Izakovic M, Mazur M, Rhodes CJ, Telser J: Role of oxygen radicals in DNA damage and cancer incidence. Mol Cell Biochem 266:37-56, 2004

23. Wesolowski JR, Rajdev P, Mukherji SK: Temozolomide (Temodar). AJNR Am J Neuroradiol 31: 1383-1384, 2010

24. Wick W, Platten M, Weller M: New (alternative) temozolomide regimens for the treatment of glioma. Neuro Oncol 11: 69-79, 2009 